\title{
Mathematical Modeling of the Flow behind Propeller
}

\author{
Oleg Solovyov $^{1}$, Vitaliy Kobrin², Sergey Yeryomenko ${ }^{2}$ \\ ${ }^{1}$ Chuguev Aircraft Repair Plant, Chuguev-1, Kharkov Region, Ukraine \\ ${ }^{2}$ National Aerospace University-Kharkov Aviation Institute, Kharkov, Ukraine \\ Correspondence: Oleg Solovyov, Chuguev Aircraft Repair Plant, Chuguev-1, Kharkov Region, Ukraine
}

Received: June 12, 2015 Accepted: July 2, 2015 Online Published: July 20, 2015

doi:10.11114/set.v2i1.956 URL: http://dx.doi.org/10.11114/set.v2i1.956

\begin{abstract}
Study of aircraft aerodynamic characteristics with operation of its power plant engines is a vital task. In this article we represent mathematical modeling of the aircraft flow with operation of its propeller. The considered mathematical model of the propeller is based on the vortex and momentum theory. Solution of the model problem of the flow behind the propeller allows obtaining of the fields of perturbed velocities in the vicinity of the aircraft and its aerodynamic characteristics. The proposed approach is aimed at simplification of the mathematical model and reduction of calculation time.
\end{abstract}

Keywords: discrete vortex method, vortex model of the propeller, aerodynamic characteristics, NEZ propeller

Nomenclature

$d$ - propeller diameter;

$V_{\infty}$ - velocity of the undisturbed flow;

$V_{1}=V_{\infty}+v_{1}-$ axis velocity on disk plane of the propeller, $\left(v_{1}-\right.$ relevant inductive velocity $)$;

$V_{2}=V_{\infty}+v_{2}-$ axis velocity on slipstream behind propeller, $\left(v_{2}-\right.$ relevant inductive velocity $) ; v_{2}=2 v_{1}$;

$r_{0}$ - propeller hub radius;

$\xi=\frac{r_{0}}{R}$, where $R=\frac{d}{2}$ - relative radius of the propeller hub;

$N$ - engine power.

\section{Introduction}

Propeller - bladed mover designed for transformation of engine torque in propeller thrust. Propellers are installed on airplanes, helicopters, snowmobiles, hovercrafts, etc. (Svishchev, 1994), therefore, the development of mathematical models for the study of aerodynamic characteristics (primarily for aircrafts with bladed mover) is a vital task.

Existing mathematical models of propellers developed on the basis of the discrete vortex method (DVM) (Belotserckovskii, Kotovsky, Nisht, Fedorov, Lifanov, 1993), allow to obtain not only aerodynamic characteristics of an aircraft with operation of its propellers, but also the characteristics of the propellers and lifting rotors. Often the mathematical modeling of propeller and lifting rotor is impossible due to the lack of geometrical characteristics, and sometimes there is no need for obtaining characteristics, for example, during the rapid assessment of the aerodynamic characteristics of the advanced aircraft. Full mathematical modeling of propeller operation is computer-intensive, and, therefore, requires considerable time to obtain the aerodynamic characteristics of aircraft.

We consider mathematical modeling based on the discrete vortex method of aircraft flow with operation of its propellers, represented by vortex schemes of propellers of N.E. Zhukovsky (NEZ), in order to reduce computer resources and time of calculation of aerodynamic characteristics of aircraft

In 1892 S.K. Dzhevetsky for the first time suggested to consider propeller blade as a wing, for example (Vetchinkin, 1913) (Figure 1). 


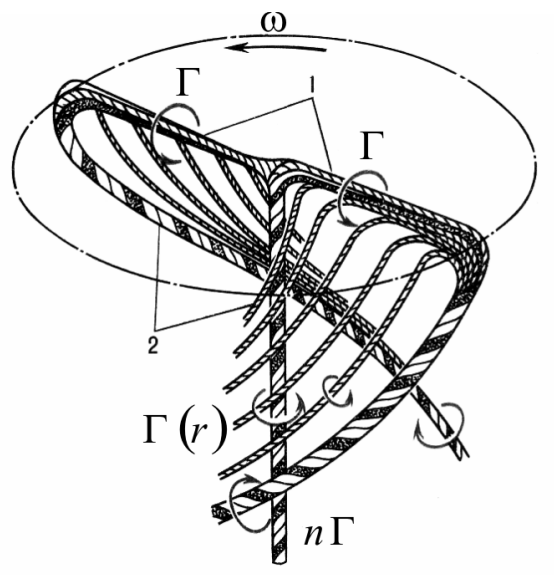

Figure 1. Vortex model of the S. K. Dzhevetsky - V. P. Vetchinkina propeller:

\section{1 - bound vortices; 2 - free vortices}

Velocity circulation $\Gamma$ is available on any closed loop that covers propeller. Wing or propeller blade can be replaced with bound vortices (Drzewiecki, 1910), as it was shown by N.E. Zhukovsky (Zhukovsky, 1937). In the simplest case, velocity circulation on the blade is $\Gamma(r)=$ const. In the center of the slipstream of n-bladed propeller central vortex is located, with circulation equal $\mathrm{n} \Gamma$. Free vortices with circulation $\Gamma$ descend down by the flow from blade tips of the propeller. This simple vortex scheme of propeller corresponds to the vortex scheme with $\Pi$-shaped vortices considered in the induced-drag theory of $\mathrm{c}_{\mathrm{xi}}$ wing (Zhukovsky, 1914).

The essence of the vortex scheme of propeller with finite number of blades $n$ (Figure 2) offered by N.E. Zhukovsky lies in its replacement by the vortex disk, which consists of radial vortex segments of finite length. It is considered that $\mathrm{n} \rightarrow \infty$. Studies (Zhukovsky, 1937) have shown that the inductive velocity, induced by disk propeller, slightly differs from the inductive velocity of bladed propeller, thus their calculation is considerably simplified.

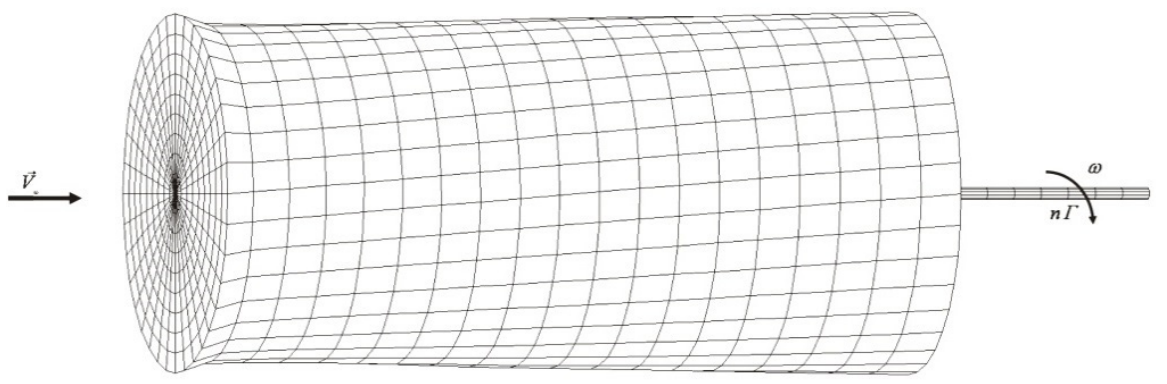

Figure 2. Vortex model of NEZ propeller $(\Gamma(r)=$ const $)$

If we consider the model of NEZ propeller, when the velocity circulation $\Gamma(r)=$ var, the vortex model of the propeller takes on form (Figure 3).

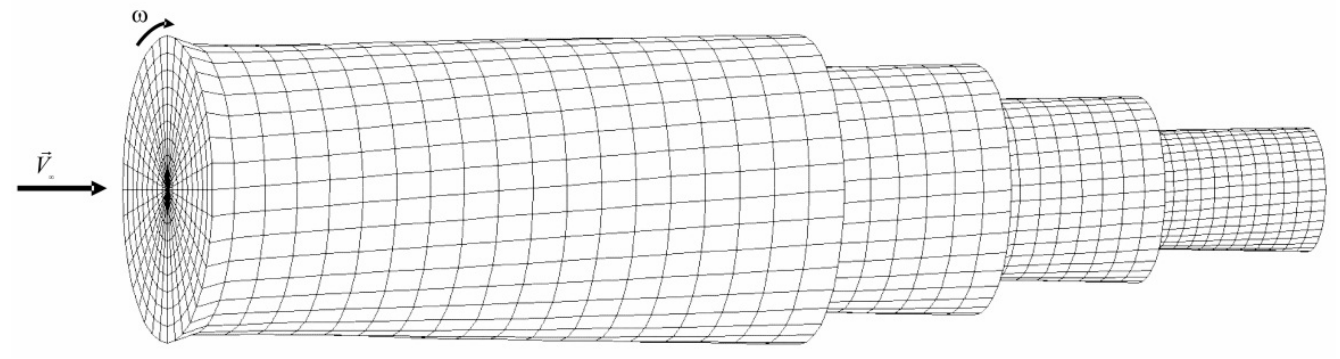

Figure 3. Vortex model of NEZ propeller $(\Gamma(r)=$ var $)$

Vortex scheme of NEZ propeller, at $\Gamma(r)=$ const is called scheme of under-stressed propeller, and vortex scheme of NEZ propeller at $\Gamma(r)=$ var - is called vortex scheme of highly-stressed propeller. Vortex model of the NEZ represented in Figure 2, as shown in (Zhukovsky, 1914), can be successfully used for simulation of the flow behind, 
even for a two-bladed under-stressed propeller.

Under-stressed propellers include propellers with rectangular or elliptic blades $(n=2 \ldots 6)$ and flight speed corresponding to $\mathrm{M}_{\infty}<0.7$. Highly-stressed propellers is scimitar-like propellers $(n \geq 6)$ that allow to obtain demanded thrust power while maintaining high figure of merit at $M_{\infty}=0.7 \ldots 0.8$ (Svishchev, 1994). Therefore, for adequate mathematical modeling of flow behind the propeller it is necessary to take into account its figure of merit and $M_{\infty}$ of flight when choosing vortex model of the propeller.

\section{Data and Results of Research}

Initial data for calculating the circulation velocity $\Gamma$ of the vortex ring is: $N$ - engine power, $V_{\infty}$ - velocity of the undisturbed flow, air-mass density corresponding to a predetermined altitude of flight $\rho_{\infty}$, rpm of propeller $n_{s}=\frac{n}{60}$, propeller figure of merit $\eta$, propeller diameter $d$, relative radius of the propeller hub $\xi$. Thus, it is possible to obtail the characteristics of the propeller, expressed in terms of dimensionless coefficients:

$$
\begin{gathered}
\lambda=\frac{V_{\infty}}{d n_{s}}-\text { propeller velocity coefficient; } \\
\bar{\alpha}=\frac{\bar{\beta} \eta}{\lambda}-\text { propeller thrust coefficient; } \\
\bar{\beta}=\frac{735.5 N}{\rho_{\infty} d^{5} n_{s}^{3}} \text { - power coefficient }
\end{gathered}
$$

From the obtained characteristics of the propeller $(\bar{\alpha}, \bar{\beta}, \lambda)$ non-dimensional circulation of velocity $\bar{\Gamma}$ of vortex ring, which model the propeller, is calculated:

$$
\bar{\Gamma}=\frac{4 \bar{\beta}}{\pi^{3}\left(V_{\infty}+v_{1}\right)\left(1-\xi^{2}\right)}
$$

where $v_{1}=\sqrt{\frac{\lambda^{2}}{2 \pi^{3}\left(2 \pi^{2}+\bar{\alpha}\right)\left(1-\xi^{2}\right)}}-\frac{\lambda}{2 \pi}-$ axial component of induced velocity.

To set the operation mode of the propeller, you can use a serial the serial propeller diagram (e.g., Figure 4)

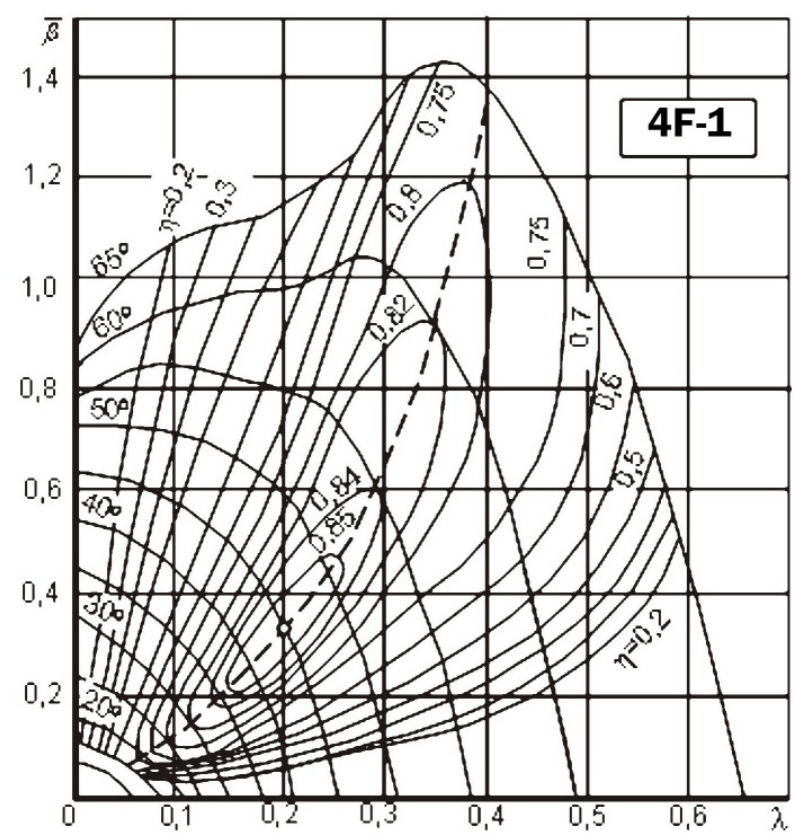

Figure 4. The serial diagram 4F-1 propeller (Kovalenko, 2007) 
Figure 5 shoys the results of the calculation of slipstream attitude, generated by isolated propeller, corresponding to different $\tau=\frac{\infty}{b}$, where $b$ - characteristic dimension (in this case - the propeller diameter $d=1$ ).

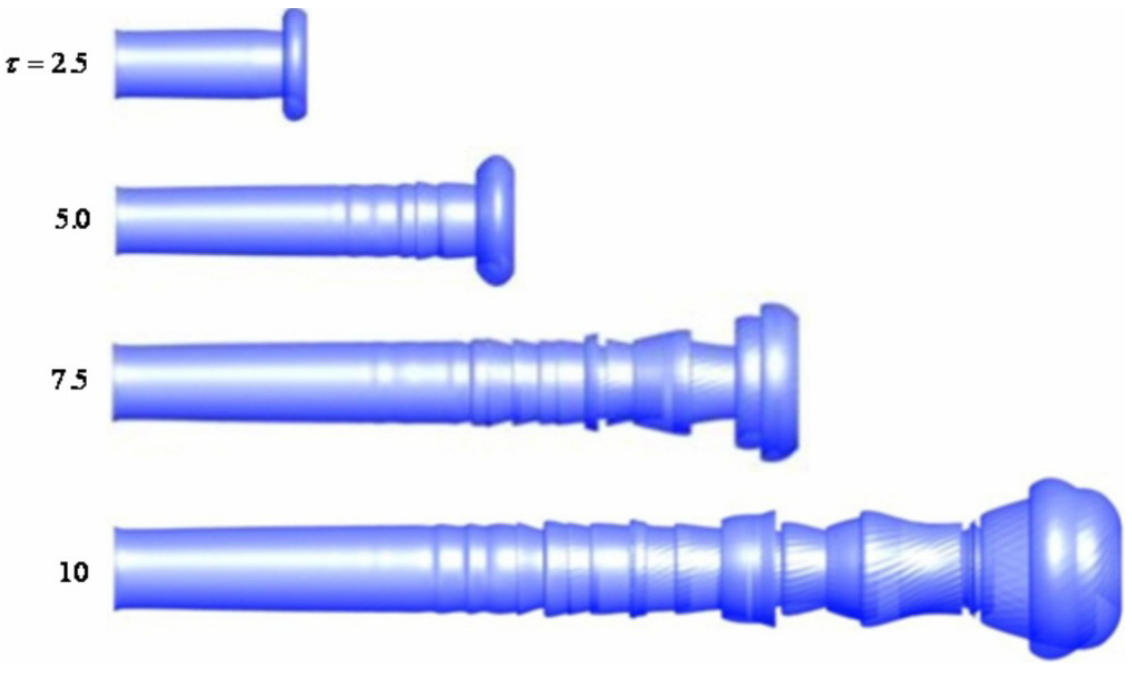

Figure 5. Slipstream of isolated perfect propeller

$$
\left(\alpha=0^{\circ}, \lambda=0.522, \bar{\alpha}=0.5, \bar{\beta}=0.3\right. \text { ). }
$$

Figure 6 shows vector field of perturbation velocity from propeller on the plane yOx.

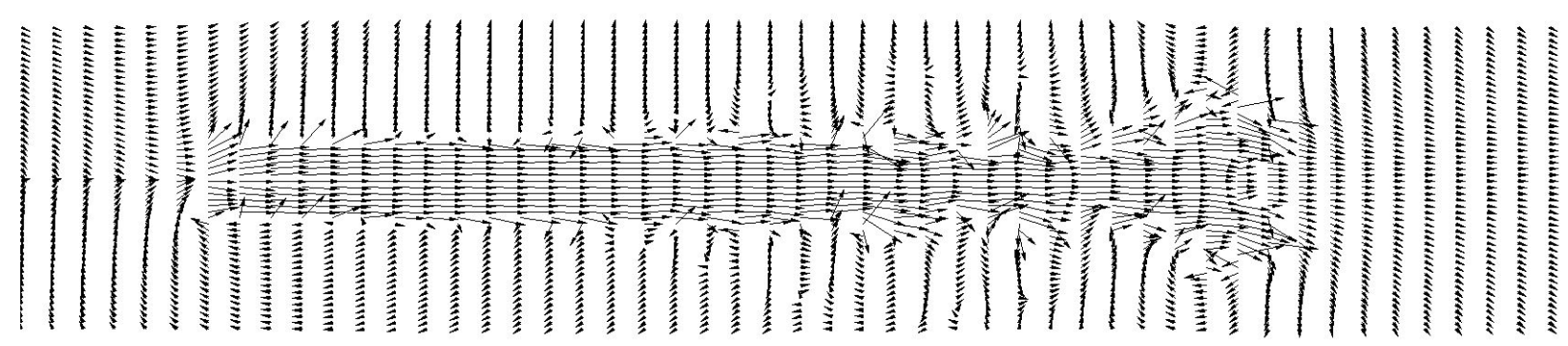

Figure 6. Vector field of perturbation velocities

Figures 7, 8 shows lines of equal velocities in the vicinity of propeller.

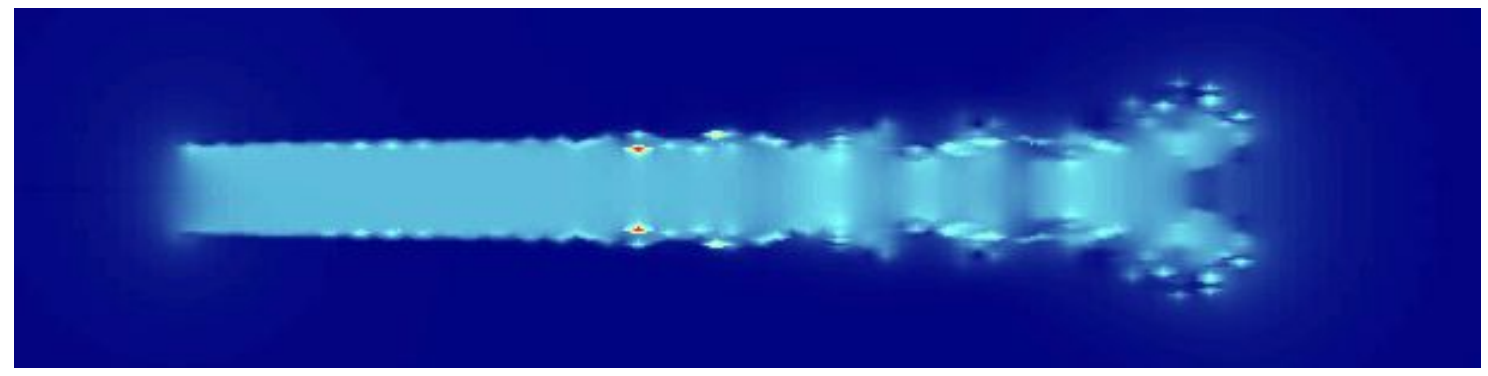

Figure 7. Lines of equal perturbation velocities in the plane yOx 


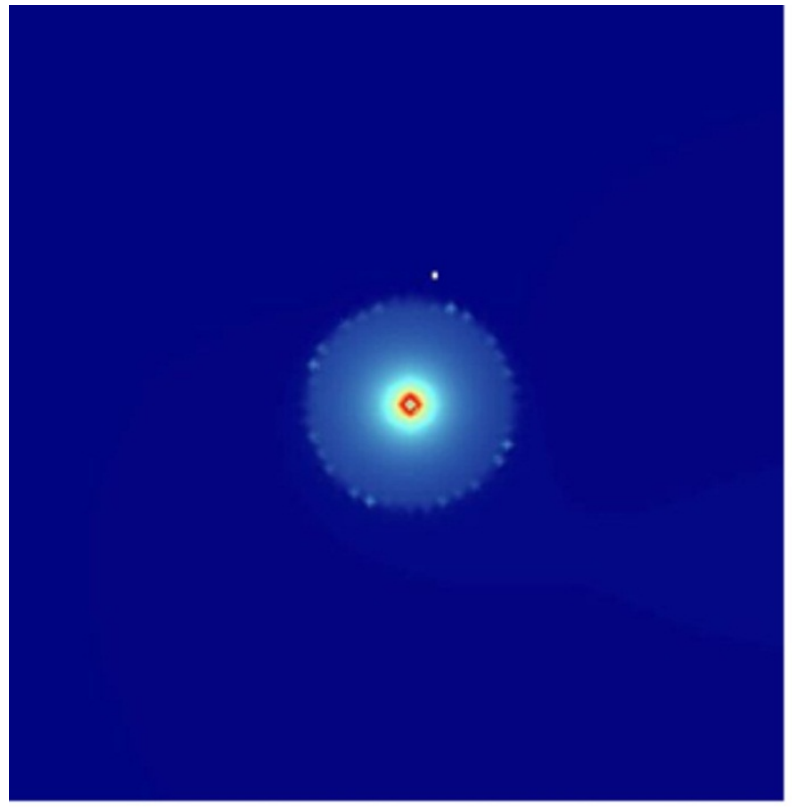

$\tau=\mathbf{3}$

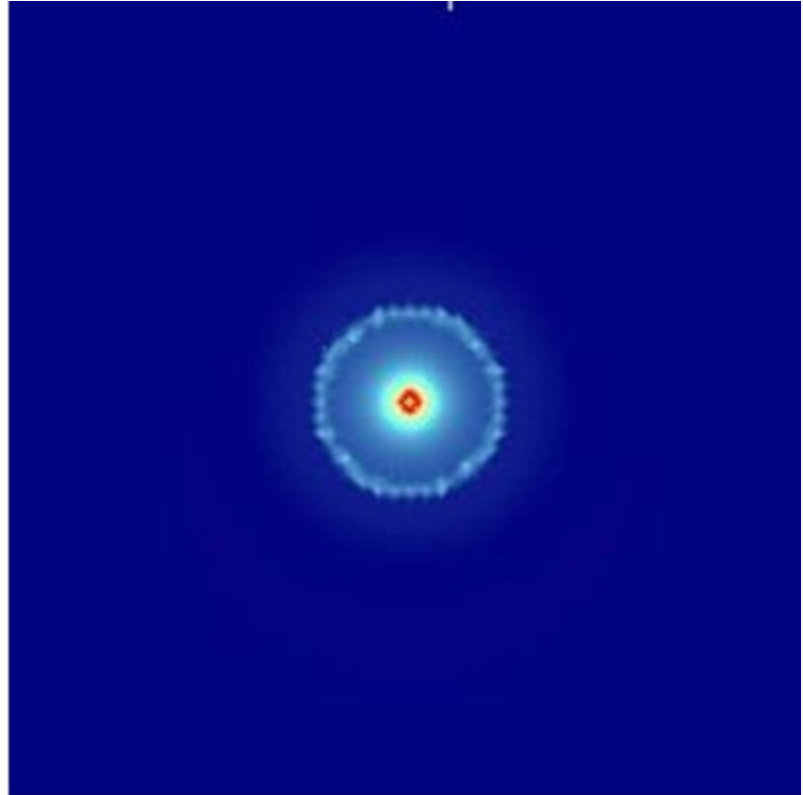

$\tau=8$

Figure 8. Lines of equal perturbation velocities in the plane yOx

Practical interest is the effect of the direction of rotation of the propeller aircraft flow pattern and its aerodynamic characteristics. The following shows some of the results of calculation of flow around the aircraft AN-140 with operation of its propellers taken into account. Figure 9 shows the projection of the prototype airplane, the mathematical model of its surface and the vortex sheet generated by its bearing surfaces.

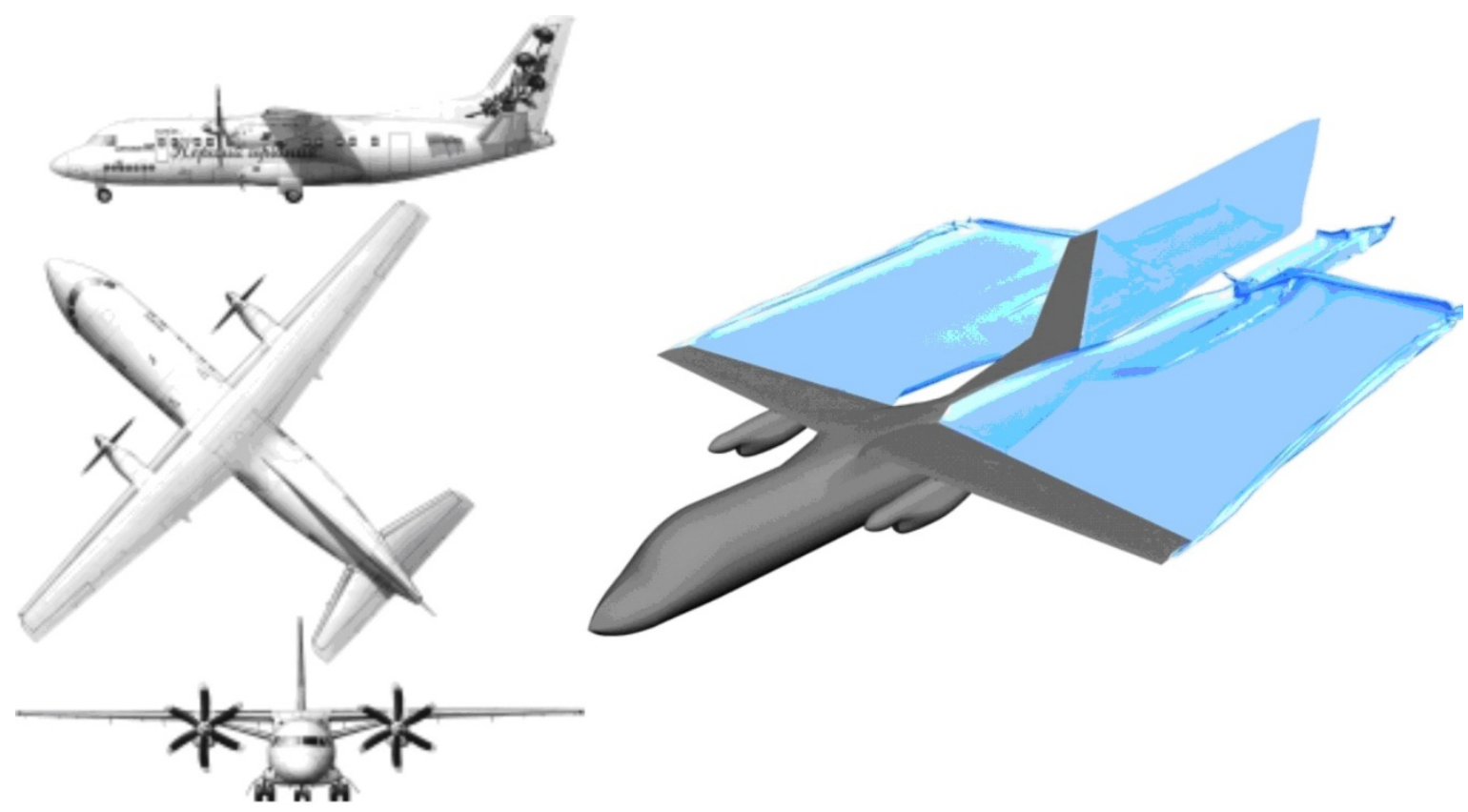

Figure 9. AN-140, flow pattern of its mathematical model without taking into account operation of propellers

$$
\left(\alpha=6^{\circ}, \beta=0\right)
$$

Calculation of flow around mathematical model of AN-140 aircraft is made in the right Cartesian coordinate system, datum point of the coefficients of aerodynamic moments coincides with the coordinate of leading edge of wing aerodynamic mean chord. Figure 10 shows the aerodynamic characteristics of the prototype airplane for the cases of its flow with propellers slipstreams taken into account and without them. 


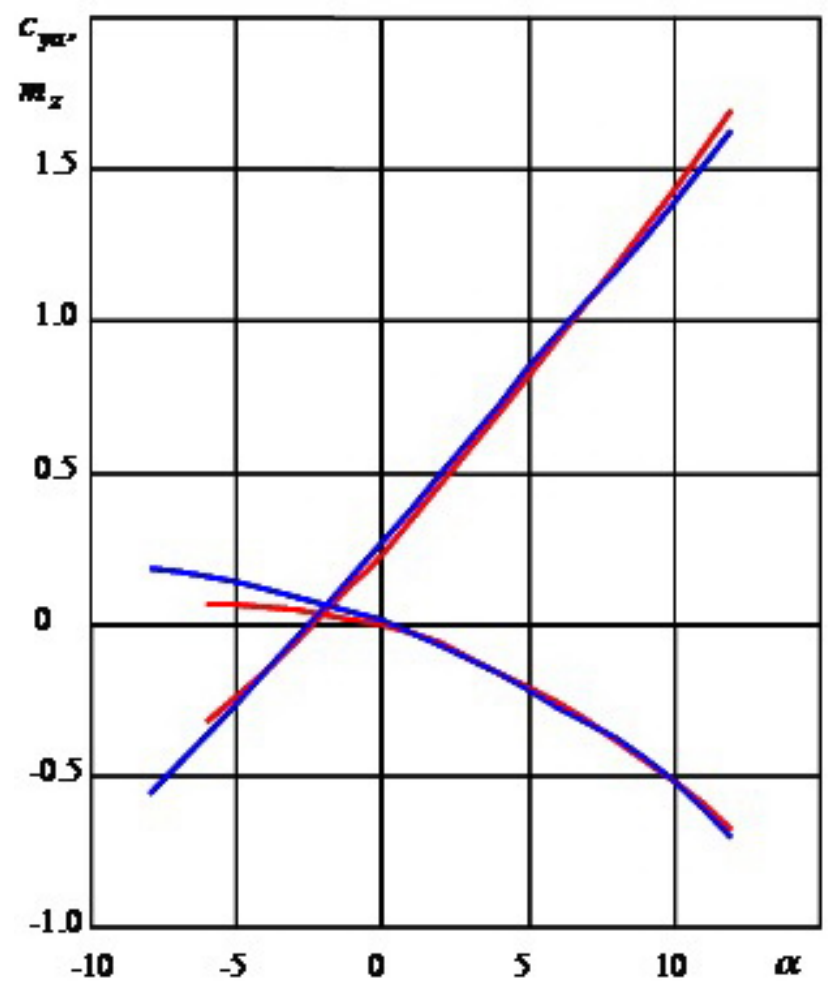

a)

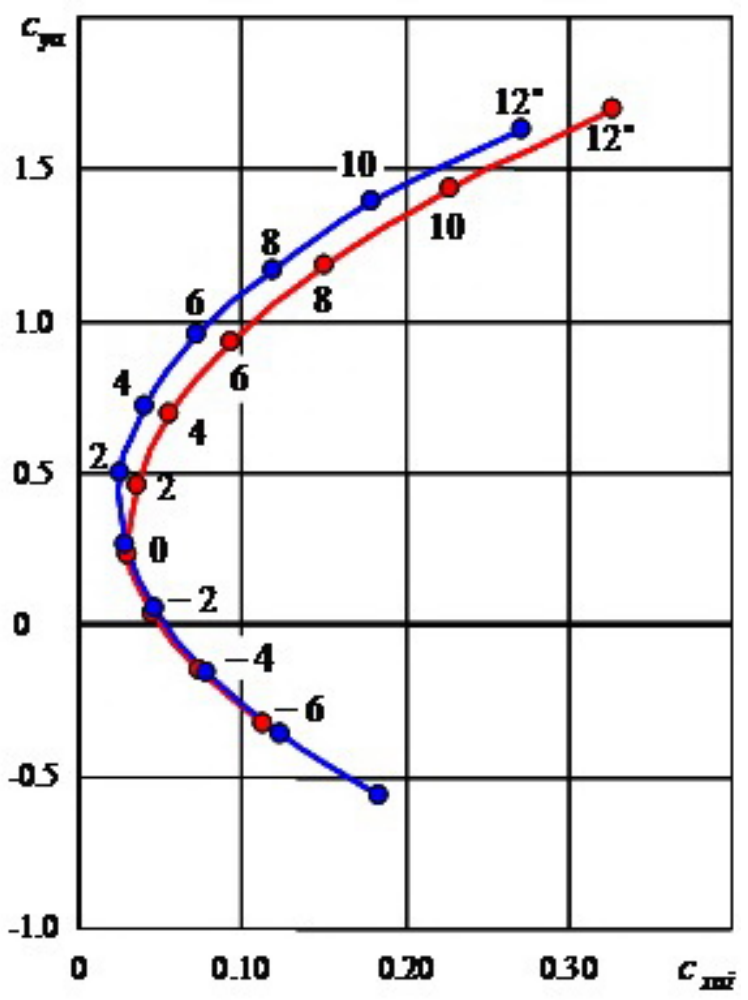

6)

- without propellers

- the right direction of propellers rotation

Figure 10. Dependencies $c_{y a}(\alpha), m_{z}(\alpha)$-(a), inductive polar curve of the first kind - (б)

Figures $11 \ldots 13$ show flow fields of prototype airplane model with a different direction of rotation of the propellers. The direction of rotation of the propellers is indicated by arrows. Propellers operation corresponds to cruising mode and is determined by the coefficients: $\bar{\alpha}=0.164, \bar{\beta}=0.322, \bar{\lambda}=1.708, \eta=0.87$, regime of flow corresponds to $\alpha=6^{\circ}, \beta=0$. 

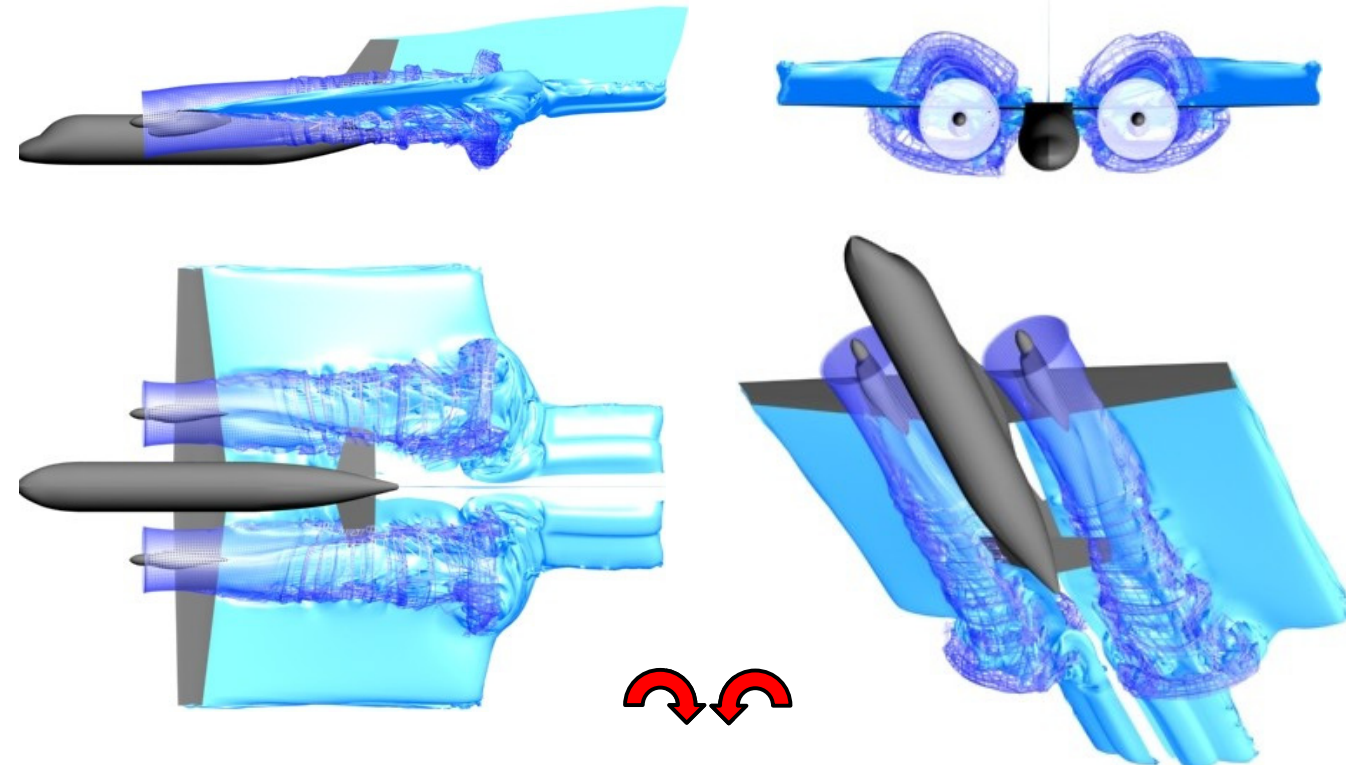

Figure 11. Vortex sheet $\left(\alpha=6^{\circ}, \beta=0, \tau=7\right)$
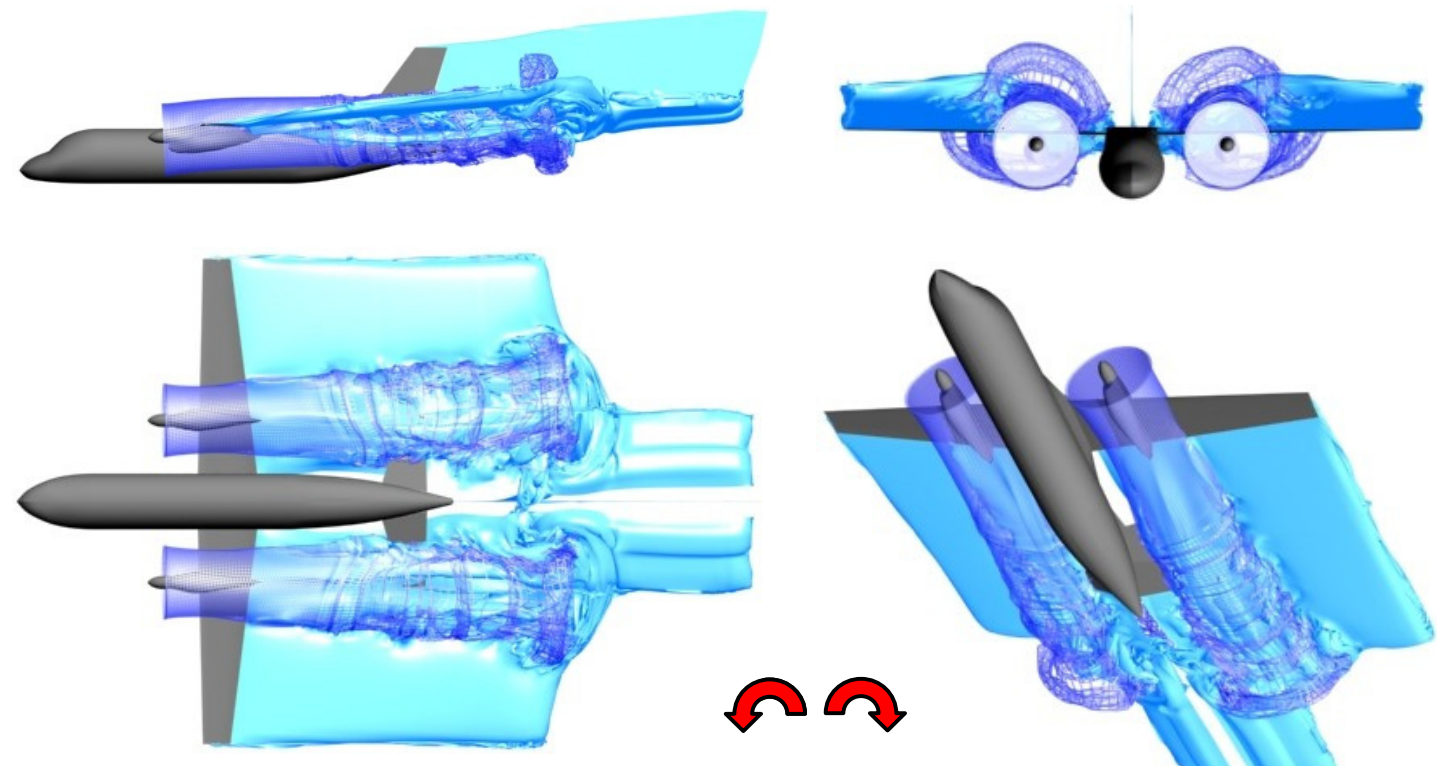

Figure 12. Vortex sheet $\left(\alpha=6^{\circ}, \beta=0, \tau=7\right)$ 


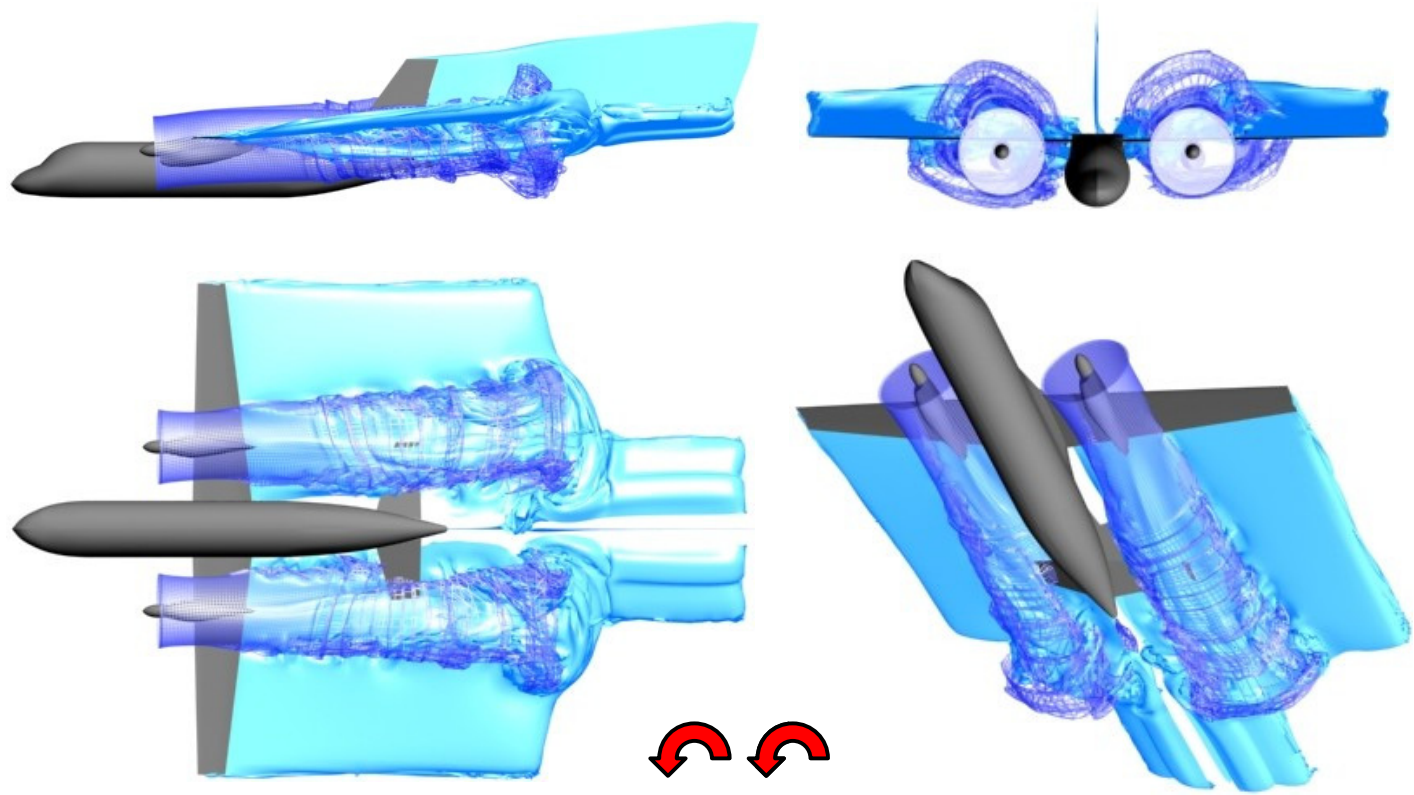

Figure 13. Vortex sheet $\left(\alpha=6^{\circ}, \beta=0, \tau=7\right)$

Figures 13 show that the flow phenomena of aircraft (symmetric or asymmetric flow around the airframe elements of the aircraft) depends on the direction of propellers rotation, which in turn can generate additional aerodynamic forces $\left(Z_{a}\right)$ and moments $\left(M_{x}, M_{y}\right)$.

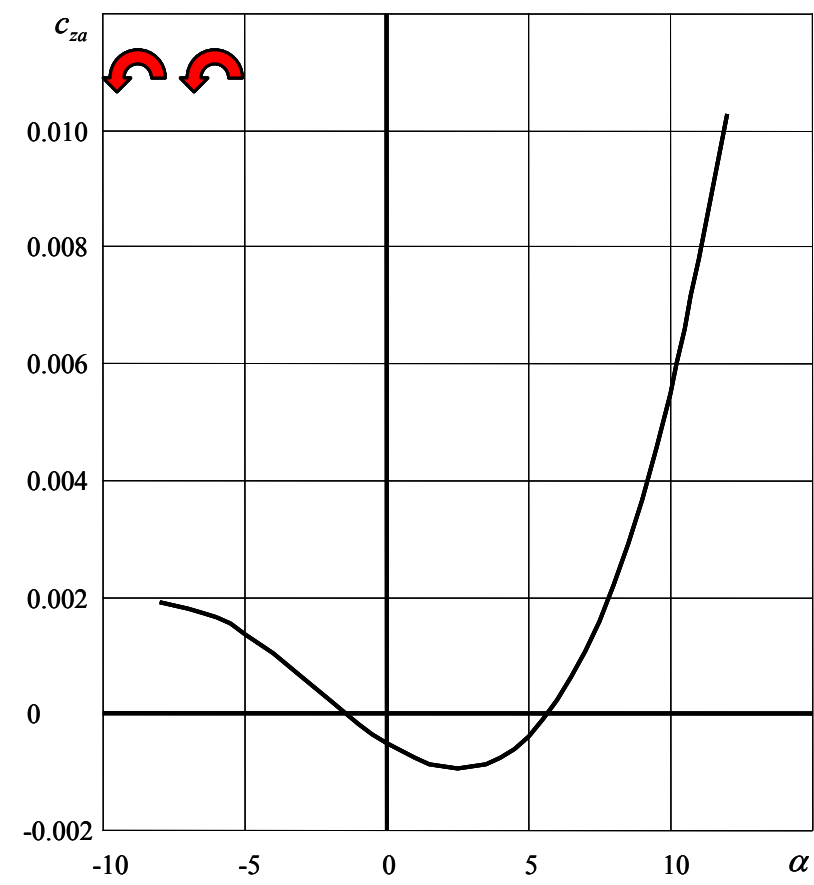

Figure 14. The dependence of side-force coefficient from the angle of attack 


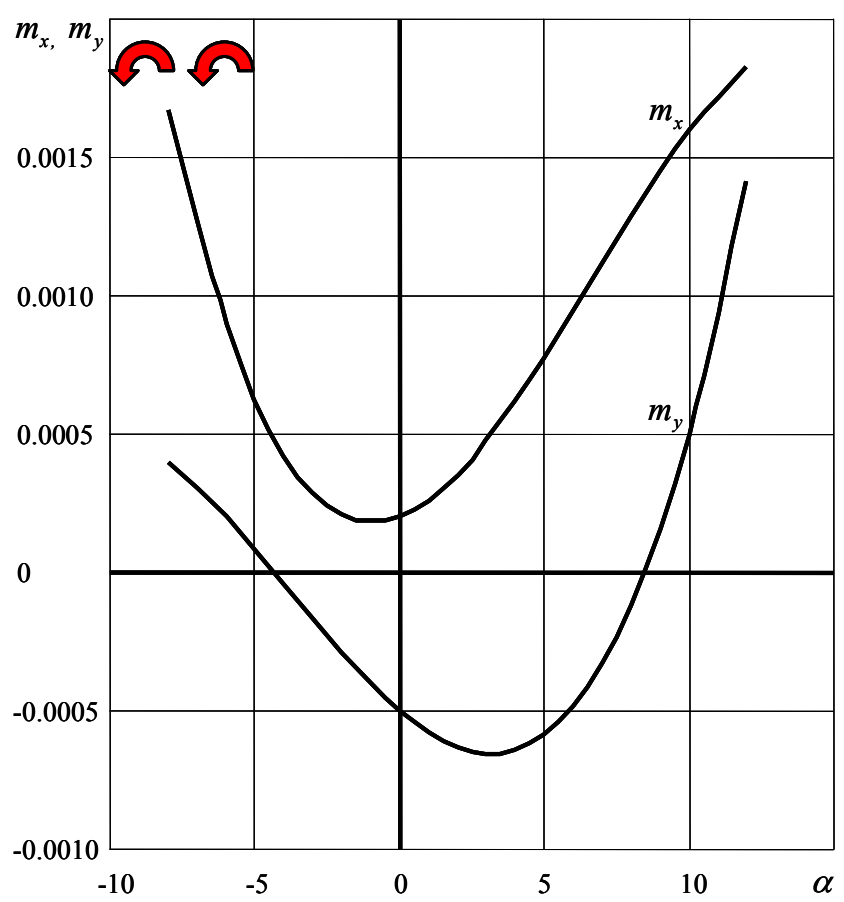

Figure 15. The dependence of roll and yaw coefficients from the angle of attack

\section{Discussion}

The presented approach of mathematical modeling of the propeller, allows obtaining of flow pattern and aerodynamic characteristics of the aircraft with operation of its bladed movers taken into account.

The direction of the propeller rotation of multi-engine aircraft power plants affects the flow phenomena of its fuselage and the bearing surfaces. Asymmetrical flow around the aircraft, caused by the propellers slipstream, generates aerodynamic roll and yaw moments to parry which it is necessary to deflect the control surfaces of the aircraft, which in turn reduces its aerodynamic efficiency.

Calculation methodology developed on the basis of discrete vortex method provides obtaining of accurate aerodynamic characteristics and may be useful in the design of advanced aircrafts with bladed movers.

\section{References}

Belotserckovskii, S. M., \& Lifanov, I. K. (1993). Method of Discrete Vortices. Boca Raton, FL: CRS Press.

Belotserckovskii, S. M., \& Nisht, M. I. (1978). Separated and attached flow around thin wings with ideal fluid. Moscow: Nauka.

Belotserckovskii, S. M., Kotovsky, V. N., Nisht, M. I., \& Fedorov, R. M. (1993). Two-dimensional separated flows. Boca Raton, FL: CRS Press.

Drzewiecki, S. K. (1910). The theory of propellers and method of their calculation. Kiev: Lubkowski Printing House.

Kovalenko, V. V. (Ed). (2007). Aerodynamics and flight dynamics of transport aircraft. Moscow: Zhukovsky Air Force Engineering Academy.

Svishchev. G. P. (Ed). (1994). Encyclopedia "Aviation". Moscow: Big Russian Encyclopedia - TsAGI.

Vetchinkin, V. P. (1913). Calculation of the screw-propeller. Bulletins of the Polytechnic Society, 5, 121-129. Moscow: Polytechnic Society.

Yuriev, B. N. (1947). Vortex theory of propellers. Moscow: Zhukovsky Air Force Engineering Academy.

Zhukovsky, N. E. (1914). Vortex theory of the propeller. Moscow: Russian Association of Printing and Publishing.

Zhukovsky, N. E. (1937). Complete Works. Vol 6. Screws, wind turbines, fans, wind tunnels. Moscow: Home Edition of Aviation Literature.

\section{(cc) EY}

This work is licensed under a Creative Commons Attribution 3.0 License. 